\title{
Supply chains and electronic markets - impulses for value co-creation across the disciplines
}

\author{
Günter Prockl $^{1}$ (D) Vikram Bhakoo $^{2} \cdot$ Christina Wong $^{3}$ \\ Received: 2 March 2017 / Accepted: 2 March 2017 /Published online: 30 March 2017 \\ (C) Institute of Applied Informatics at University of Leipzig 2017
}

\section{Electronic markets and supply chains}

This special issue of Electronic Markets was planned with the intention to connect the research domains of information management (IM) and supply chain management (SCM). Such a connection intuitively makes sense as both areas have a joint history for quite a while. They go hand in hand since the time when the term logistics management was coined in the late $80 \mathrm{~s}$ and the field took the leap from being a functional, engineering oriented discipline towards taking a more integrated view of managing relationships, coordinating flows or processes (Bowersox 2007). Supply chains, in its classic definition by Mentzer et al. (2001, p. 4) understood as "... set(s) of three or more entities (organizations or individuals) directly involved in the upstream and downstream flows of products, services, finances, and/or information from a source to a customer" contain different actors, they are complex and this implies a lot of interaction which needs support also by means of "electronics". Prockl (2007)

Günter Prockl

gp.om@cbs.dk

Vikram Bhakoo

vbhakoo@unimelb.edu.au

Christina Wong

christina.wy.wong@polyu.edu.hk

1 Department for Operations Management, Copenhagen Business School, Solbjerg Plads 3, 2000 Frederiksberg, Denmark

2 Department of Management and Marketing, University of Melbourne, 198 Berkeley Street, Carlton 3010, Australia

3 Business Division, Institute of Textiles and Clothing, The Hong Kong Polytechnic University, Hung Hom, Kowloon, Hong Kong shows that supply chain practitioners consider management of information flows far more challenging to manage compared to physical or financial flows. The notorious bullwhip effect, usually taught in the first SCM lectures, (see Tröger and Alt in this issue), is tackled with Collaborative Planning and Forecasting methods or the sharing of Point-of-SalesData. Technological innovations such as 3D printing and direct manufacturing, eCommerce and Homeshopping have been discussed as supply chain disruptors. Recent discussions under the term Internet of Things deal with the digital transformation of supply chains and their management on the basis of their digital copy. The Germans discuss cyber physical systems and their impact on the supply chains under the metaphor of an Industry 4.0 which basically connotes an industrial revolution. Blockchain technologies are supposed to revolutionize documentation and transactions within the chain, thus simplify safeguarding and governance and maybe cause a changing actor structure within supply chains (Korpela et al. 2017). It is thus safe to conclude that electronic markets are highly relevant and impactful to a modern supply chain. Although SCM has grown and matured over time, questions about structure, the scope of the researched supply chain and theoretical underpinning of the field are big and vexing questions. This leads to ongoing debates about whether SCM qualifies to be labelled as a discipline. Whilst, we recognise that the question above is a pertinent one, we do not seek to provide a silver bullet solution to it; however we aim at identifying synergies between IM and SCM. We would like to briefly highlight general thoughts to the identity of SCM, what it may contribute to electronic markets - and vice versa. Doing so we extract some reference points for the collaboration among the disciplines and underpin the motivation for focus and positioning of this special issue at the interface between SCM and electronic markets. 


\section{SCM as discipline - Reference points for further research}

Quite a number of SCM scholars have discussed maturity level and identity of SCM as an academic discipline (Halldorsson et al. 2015; Ellram and Cooper 2014; Chicksand et al. 2012; Defee et al. 2010; Halldorsson et al. 2007; Prockl 2007). In summary they conclude that SCM still does not fully meet the criteria of what constitutes a discipline (Fabian 2000) and detect a lack of "clear research norms," (Chicksand et al. 2012, p 468) and a very low level of inductive research. Scholars have also discussed whether methodological rigor may be seen as a compensation for clarity about the research objective and whether quantitative models dominate the field of supply chain management. However the lack of inductive research appears particularly embarrassing as the discussions also indicate that the "... field has not yet developed a rich and robust theoretical grounding (Ellram and Cooper 2014, p 16)". Theoretical foundations for the research is primarily based on a concept which Stock (1997) named theory borrowing. Related "theory candidates" for SCM, such as theories from the organization sciences (Ketchen and Hult 2007,2011 ) or a "unified theory" by subordinating different theories under the umbrella of a capability approach (Mentzer et al. 2004), are discussed in the literature (Halldorsson et al. 2015; Prockl 2007). Such a proliferation of theory comes according to Pfeffer (1993) not without problems and the discipline resembles in consequence "more a weed patch than a well tended garden" (ebd. p. 61). Without sharper boundaries of its theoretical core, SCM is at risk at remaining a vague catchall term without a robust theoretical anchor. Its contours get even fuzzier in contrast to other disciplines e.g. a marketing related Service Dominant Logic (e.g. Lusch et al. 2010) that also deals with relationships and different actors within network environments but presents a more coherent core in forms of formulated propositions.

\section{Conceptualizing supply chain management}

In search for a "core", a common understanding of a SCM, Halldorsson et al. (2015) identified the "integrative nature" of SCM as a consistent theme within the literature which would distinguish it from its original fields of logistics, purchasing and operations management. They see SCM further characterized as a boundary spanning, an interorganizational phenomenon (Halldorsson et al. 2015; Giannakis and Croom 2004). This view which Bechtel and Jayaram have described already in Bechtel and Jayaram 1997 under the term Awareness School, assumed a certain consensus that the attainment of the objectives pursued by SCM requires a chain-wide, "holistic" consciousness in the sense of "... shared vision of market opportunity". Related objectives include the creation of higher customer satisfaction through reduced turnaround times and lower costs, and ultimately increasing the success of the companies involved. Closely related to this is the belief that higher overall efficiency through exchange of data and joint planning is possible along the entire chain.

One problem with this understanding might be however that a supply chain is not per se such a "holistic" thing. The scope of our conceptualization is a matter of definition. In Mentzer et al.'s definition we see such a holistic thing when we have three or more units. Real supply chains are way more complex and contain many more stakeholders and echelons. This means that SCM intends to allocate resources across independent actors and at the same time needs to integrate these autonomous roles and actors to something holistic in the sense of a "total optimum". This is of course difficult and in consequence the scope remains limited. On a similar note, Ellram and Cooper (2014) report accordingly about emerging developments towards collecting data from triadic relationships based on in depth case studies. For information sharing, Kembro and Selviaridis (2015) conclude that results and implications of information sharing in a supply chain are often reported on the supply chain level however the main body of information sharing literature typically investigates dyadic buyer-supplier relationships. They conclude about predominant focus on dyads and explain it with a limited view of researchers.

The other related problem refers to the labels around supply chain. Some research refers to a demand chain instead of a supply chain, others call it a supply network (Harland et al. 2001), or a supply chain network (Tokman and Beitelspacher 2011), an extended enterprise (Karlsson 2003) or more recently to an ecosystem (Ben Letaifa 2014). We cite Ellram and Cooper (2014) who conclude that there is "a fairly wide agreement that companies really have networks of suppliers rather than 'chains'. So, realistically we are not capturing the boundary of the supply chain holistically. However as the term got embedded in the language Ellram and Cooper (2014) assess it as unlikely that theory or practice would substitute the term. We are not too sure about this assessment but we fully agree with their claims that there needs to be clarification about the researched object either being as chain like dyad or a multidirectional network and the need for more careful positioning of work "within the realm of SCM, rather than implying that researchers are studying the entire supply chain as unit of analysis.

Based on the discussion above we have a paradoxical situation. Applying Mentzer et al.'s (2001) definition we need at least three independent actors to constitute a supply chain. Most research however conceptualizes SCM as dyadic relationships and often from the viewpoint of a focal firm. Organisations and their associated business models compete not only with organisations in other supply chains but also with the business models of the actors within the same supply chain. Apple and Samsung illustrated this in the mobile phone 
and tablet pc market. The resource based view, for example, applied on a company level provides significantly different results than research applied on the level of a chain or network. Based on this, we could ask a provocative question, whether a supply chain management with an emphasis on the dyadic relationships and focal character of single actors is really researching the management of supply chains?

\section{Impulses for value co-creation across the disciplines}

Though IM researchers may have a similar discussion about their research identity, they still own a domain which is based on information and communication technologies (ICT) and solution approaches. However while research on SCM is often characterized as dyadic - or emerging as triadic, and thus not really reflecting the claim of a holistic view, the more technology oriented IM approaches often demonstrate the opposite. In regards to SCM they appear often too holistic, thus neglecting the individual actors' position, role and business interests.

For example, it appears intuitively convincing that supply chain visibility improves the performance of a supply chain. However in fact, the scientific support for the performance effect is not that clear yet (Caridi et al. 2010). Steinfield et al. (2011) reviews a list of IT solutions supposed to eliminate information transparency problems in global supply chains and reaches the conclusion that these have failed because of low adoption, particularly among smaller enterprises as well as amongst the more remote or peripheral members of supply chains (e.g., transportation companies and customs agencies). Kembro and Näslund (2014) review empirical literature and identify two camps in the journal landscape. One understands information sharing as great idea per se and the other emphasizes the general risk and cost of sharing information. Based on the latter they finally discuss whether information sharing in the chain is not only a myth. Dwelling deeper into the drivers of technology implementations, Bhakoo and Choi (2013) investigate how institutional and endogenous pressures affect technology implementations and whether inter-organizational information systems (IOS) are for instance largely implemented in a "ceremonial" way. They show how organizations embedded within different tiers of a health care supply chain would respond differently to the institutional pressures to implement IOS, largely because they have their own, unique set of norms, business practices and administrative complexities. In its essence, this all indicates a limited view on the individual actors, their context and their perception of value and it contains a limited view about the cocreation of such value.

In reference to Bechtel and Jayaram (1997) schools of thought, one could also say that SCM literature is dominated by a linkage school and a focal actor while ICT literature often suffers in the view of SCM scholars by a too dogmatic or naïve form of an integration schools which claim to "optimize" the chain as a whole. The latter seems to be blind in regards to the resource and task allocation across different actors and the complexity of their integration into a coherent whole in order to create value (Wong et al. 2011a, b, 2015). Many contributions about information management in the supply chain thus often appear as a relapse to the cooperation-romanticism and the win-win discussions in supply chain management of the 90 s.

\section{Value and emergence in ecosystems}

Before we now get "lapidated" for complaining about putative deficits of the IM disciplines we admit that the issue has been already addressed. Major impulses for this may have their origin in the development of innovative IT services, related business models and the associated questions on value, value propositions and value-co-creation. We see in particular the view on value creation at the center of our interest. Ben Letaifa (2014) postulates with reference to Payne et al. (2008), Cova and Salle (2008), Mele and Polese (2011), Normann and Ramirez (1993), that value-(co) creation is just not a linear economic process taking place in a specific production chain but an emergent process involving multiple actors (Pitelis and Teece 2009), including customers and competitors (Normann and Ramirez 1993). It is thus not restricted to a dyad but a multilevel experience involving the multiple actors in continuous interactions (Payne et al. 2008).

The conceptual frame for these emergent processes is the business ecosystem which is different to a supply chain defined as a more "loosely connected business community made up of different levels of organizations that share a common goal and co-evolve with each other". (Rong et al. 2015) This implies - similar to a supply chain - a community that consists of various levels of interconnected participants who depend on each other for their mutual effectiveness and survival and thus also share their fate with each other (Ianiti and Levien 2004:8). The interdependent firms co-evolve in an ongoing cycle and constantly renew themselves. (Liu and Rong 2015). In particular the dynamic view that comes with this ecosystems approach is an interesting contrast to the more static view we have in SCM. (Liu and Rong 2015). While SCM has the holistic, integrated flow as a consistent theme and thus aims more on a tight integration of the supply chain, ecosystem approaches put an emphasis on the diversity of loosely connected and emerging structures and their dynamics beyond the dyadic integration. One may see ecosystems more prone to a bottom up approach while SCM is basically dominated by a top-down view which is centered on the focal firm with its dyadic partners.

Though we conceive ecosystems in some contrast to supply chains we do not necessarily see a substitution or a 
transition from supply chains to ecosystems (Ben Letaifa 2014), but understand ecosystem thinking more as a complementary anti pole and both together creating a field of tension. The holistic claim, the customer oriented view of a supply chain and the integration efforts organized by strong focal actors may be challenged by the mechanisms that facilitate or restrict the "holistic" and so open new and fruitful research avenues.

Rediscovering the questions on how supply chains develop, emerge and continuously reinvent themselves may help to better understand, what it basically is, that holds them together and so indicate elements that may sharpen the identity of supply chain management research.

Related approaches require a closer view on the individual actors as constituting elements of the network and on the different forms of interactions between them. More detailed differentiation by analysing specific roles of actors within the network, their position and agency, lock-in, or path dependencies as influencing factors may provide a more realistic understanding of the internal configuration and development of a supply chain (Ekman et al. 2016).

Moving beyond the dyadic perspective into ecosystems will require measures, classifications and typologies beyond the pure description to how they can be empirically measured. Such a view into real life and emerging supply chains may require other methods and approaches and may also fill the above mentioned gap of inductive research.

\section{Focus of the Special Issue - Interactions in Supply Chains}

Having identified how IM and supply chain share a symbiotic and yet complex relationship, our objective was to understand how each of these disciplines informs the other and facilitates addressing the challenges organizations face. We need to realise that a one size does not fit all, e.g. in terms of standards (Bhakoo et al. 2015) and that issues such as regulations (Weingarten et al. 2015), roles of professional associations and maturity of organizations in their implementation of technology matter. These circumstances are increasingly relevant in the current world. We therefore believe that it is important to researchers and practitioners to understand these "interactions" in a setup which is less restricted to dyads but conceptualized as a multilevel experience involving multiple actors (Payne et al. 2008).

With our special issue we intended to open the view towards such topics by explicitly asking for interactions as sources of new business models, innovations and also how they facilitate building resilience in managing risks and disruptions. In particular we were interested in how these interactions create or alternate the dynamics of service provision in different (electronic) markets and industries. And we were in particular keen on submissions that take the supply chain as their unit of analysis and thus go beyond the organization to include dyadic, triadic or network level of analysis.

The call for papers generated an impressive number of submissions but not all of them met the criteria of the specific focus on supply chain management and interactions across multiple actors. It also turned out that the reviewing process, at the interface between disciplines with having editors and reviewers from different communities and backgrounds, can be daunting. After two or three rounds of review three papers were accepted. The papers include case studies and action research in various countries. Collectively, the studies address the issues of using IT to facilitate services in supply chain by enabling visibility and involving multiple parties in information sharing and communication.

The first paper of our special issues, written by Tröger and Alt, is titled: "Design Options for Supply Chain Visibility Services - Learnings from Three EPCIS". Information transparency across multiple echelons in the supply chain is one of the hallmarks of a robust and resilient supply chain. This paper addresses the issue of applying GS 1 standards particularly electronic product code information services (EPICS) across multi-tier supply chains to address information transparency issues. This paper is an excellent fit within the special issue as it discusses the issue of technology standards within a supply chain context. Furthermore, the functionality and the application of EPCIS is extended across a number of industries such as DHL, Thyssen Krupp and GS 1 Germany. Since the implementation of EPICS cuts across different industries we can see how the implementation of standards requires modification and customisation. From a methodological perspective the interfaces theme is relevant as the paper employs qualitative research methodology but embraces the diversity in qualitative methods by using case studies and action research. The significant advantages of implementing EPCIS-based visibility services is that it enables disclosing information on a number of events and related attributes such as quantity, location and identity, real time visibility of data, conducting queries and automatic triggering of business processes such as notification of process owner. The potential of these applications can facilitate mitigating the bull whip effect and can be extended across wide range of applications and industries." The paper opens the door to applying and understanding the EPCIS standards across diverse industries and different entities across the supply chain.

Elbert, Pontow, and Benlian examine the best practices of inter-organizational information systems (IOS) in maritime transport chains. They argue that IOS guarantee timely, costefficient, and accurate information flows among various organizations in maritime transport chains. Through two embedded single case studies, Elbert et al. reveal the role of IOS by examining how IOS facilitates information exchange across key stakeholders (i.e. transport- and transhipment 
organizations) in maritime transport chains. Elbert et al. modelled inter-organizational business processes of transport chains using Business Process Modelling Notation (BPMN) in maritime transport chains to analyse how information is exchanged across key stakeholders. The authors identified the inter-organizational business processes for outgoing and incoming containers, sharing of information via IOS, and junctures to provide potentials for process innovations. This study examined the transport- and transhipment processes along maritime transport chains and hinterland transportation by rail to reveal how maritime transport chains work on a granular business process level.

Elbert et al. provide insights into processes and communication interfaces across organizations involved in hinterland transportation by rail in the context of maritime transportation. The findings show that the communication and information flows along maritime transport chains are complex and IOS plays a crucial role in facilitating the flows. Elbert et al. call for further research of innovative electronic platforms and standards of future IOS to improve information flows across the stakeholders (e.g., deep sea carrier, freight forwarder) to facilitate their communication and information sharing. The authors argue that a consequent implementation of IOS based commissioning systems and trustful information sharing between organizations in maritime transport chains is beneficial by offering transparency in processes to allow consignors to track and trace the movement of their containers.

The third paper authored by Papert and Pflaum has the title "Development of an ecosystem model for the realization of Internet of Things (IoT) services in Supply Chain Management". The primary objective of the explorative paper is the investigation of "general structures of an ecosystem in order to implement IoT services". Essentially the authors want to identify key actors in such ecosystems and try to isolate their different specific roles. This links in so far very well to this special issues' focus on interactions as the authors thus research the structural arena in which interactions and the value creation within the ecosystems are supposed to happen. The focus of the research is hereby on information services that connect the material flows of a supply chain to the related information flows. Such information services may be provided in particular by logistics service providers. In general, the view on ecosystems provides a dynamic view and the roles and interactions of the different actors involved are a continuous source for the development and renewing of the ecosystem. Such a dynamic view is in some contrast to the more static view of traditional supply chain management (Liu and Rong 2015) and may lead to interesting and new research avenues also for the supply chain management research.

Though the paper is based on empirical data, the emphasis of the paper of Papert and Pflaum is less on the implementation of ecosystems. Instead the authors aim at a theoretical model that is supposed to help companies to better understand the implementation of IoT services. Papert and Pflaum apply a grounded theory approach and the setup and application of their approach takes a prominent role in the paper.

\section{Thank you editorial team and reviewers}

Finally we want to express our great appreciation to the Editors in Chief Rainer Alt and Hans-Dieter Zimmermann and the Executive Editor Carsta Militzer-Horstmann for initiating this special issue and all the great support in developing it. We also thank all the reviewers who repeatedly invested their time, ideas and knowledge to improve the submissions by providing timely and constructive comments.

Günter Prockl, Vikram Bhakoo and Christina Wong.

\section{References}

Bechtel, C., \& Jayaram, J. (1997). Supply chain management: A strategic perspective. International Journal of Logistics Management, 8(1), $15-33$.

Ben Letaifa, S. (2014). The uneasy transformation from supply chains to ecosystems. Management Decision, 52(2), 278-295.

Bhakoo, V., \& Choi, T. (2013). The iron cage exposed: Institutional pressures and heterogeneity across the healthcare supply chain. Journal of Operations Management, 31(6), 432-449.

Bhakoo, V., Singh, P. J., \& Chia, A. (2015). Supply chain structures shaping portfolio of technologies: Exploring the impact of integration through the "dual arcs" framework. International Journal of Physical Distribution and Logistics Management, 45(4), 376-399.

Bowersox, D. J. (2007). SCM: The past is prologue. CSCMP's Supply Chain Quarterly, Quarter, 2, 28-33.

Caridi, M., Crippa, L., Perego, A., Sianesi, A., \& Tumino, A. (2010). Measuring visibility to improve supply chain performance: a quantitative approach. Benchmarking: An International Journal, 17(4), 593-615.

Chicksand, D., Watson, G., Walker, H., Radnor, Z., \& Johnston, R. (2012). Theoretical perspectives in purchasing and supply chain management: An analysis of the literature. Supply Chain Management: An International Journal, 17(4), 454-472.

Cova, B., \& Salle, R. (2008). Marketing solutions in accordance with the S-D logic: Co-creating value with customer network actors. Industrial Marketing Management, 37(3), 270-277.

Defee, C., Williams, B., Wesley, S., \& Rodney, T. (2010). An inventory of theory in logistics and SCM research. International Journal of Logistics Management, 21(3), 404-489.

Ekman, P., Raggio, R., \& Thompson, S. (2016). Service network value co-creation: Defining the roles of the generic actor. Industrial Marketing Management, 56(5), 51-62.

Ellram, L., \& Cooper, M. (2014). Supply chain management: It's all about the journey, not the destination. Journal of Supply Chain Management, 50(1), 8-20.

Fabian, F. (2000). Keeping the tension: Pressures to keep the controversy in the management discipline. Academy of Management Review, 25(2), 350-371.

Giannakis, M., \& Croom, S. (2004). Toward the development of a supply chain management paradigm: A conceptual framework. Journal of 
Supply Chain Management: A Global Review of Purchasing \& Supply, 40(1), 27-37.

Halldorsson, A., Kotzab, H., Mikkola, J. H., \& Larsen, T. S. (2007). Complementary theories to supply chain management. Journal of Supply Chain Management, 12(4), 284-296.

Halldorsson, A., Hsuan, J., \& Kotzab, H. (2015). Complementary theories to supply chain management revisited - from borrowing theories to theorizing. Supply Chain Management: An International Journal, 20(6), 574-586.

Harland, C., Lamming, R., Zheng, J., \& Johnsen, T. E. (2001). A taxonomy of supply networks. Journal of Supply Chain Management, 37(4), 21-31.

Ianiti, M., \& Levien, R. (2004). The keystone advantage - What the new dynamics of business ecosystems mean for strategy, innovation, and sustainability. Boston: Harvard Business School Press.

Karlsson, C. (2003). The development of industrial networks - challenges to operations management in an extraprise. International Journal of Operations \& Production Management, 23(1), 44-61.

Kembro, J., \& Näslund, D. (2014). Information sharing in supply chains, myth or reality? A critical analysis of empirical literature. International Journal of Physical Distribution and Logistics Management, 44(3), 179-200.

Kembro, J., \& Selviaridis, K. (2015). Exploring informations sharing in the extended supply chain: an interdependence perspective. Supply Chain Management: An International Journal, 20(4), 455-470.

Ketchen, D., \& Hult, T. (2007). Bridging organization theory and supply chain management: The case of best value supply chains. Journal of Operations Management, 25(2), 573-580.

Ketchen, D., \& Hult, T. (2011). Building theory about supply chain management: Some tools from the organizational sciences. Journal of Supply Chain Management, 47(2), 12-18.

Korpela, K., Hallikas, J., \& Dahlberg, T. (2017). Digital Supply Chain Transformation toward Blockchain Integration. In Proceedings from $50^{\text {th }}$ Hawaiian International Conference on System Sciences, Hawaii.

Liu, G., \& Rong, K. (2015). The nature of the Co-evolutionary process: Complex product development in the mobile computing Industry's business ecosystem. Group \& Organization Management, 40(6), 809-842.

Lusch, R. F., Vargo, S. L., \& Tanniru, M. J. (2010). Service, value networks and learning. Journal of the Academy of Marketing Science, $38,19-31$.

Mele, C., \& Polese, F. (2011). Key dimensions of Service Systems in Value-Creating Networks. In H. Demirkan, J. C. Spohrer, \& V. Krishna (Eds.), The science of service systems. New York: Springer.

Mentzer, J. T., DeWitt, W., Keebler, J. S., Min, S. H., Nix, N. W., Smith, C. D., \& Zacharia, Z. G. (2001). Defining supply chain management. Journal of Business Logistics, 22(2), 2-25.
Mentzer, J. T., Min, S. H., \& Bobbitt, L. M. (2004). Toward a unified theory of logistics. International Journal of Physical Distribution and Logistics Management, 34(8), 606-627.

Normann, R., \& Ramirez, R. (1993). From value chain to value constellation: Designing interactive strategy. Harvard Business Review, 71, $65-77$.

Payne, A. F., Storbacka, K., \& Frow, P. J. (2008). Managing the Co-creation of value. Academy of Marketing Science Journal, 36(1), 83-96.

Pfeffer, J. (1993). Barriers to the advance of organizational science: Paradigm development as a dependent variable. Academy of Management Review, 18(4), 599-620.

Pitelis, C. N., \& Teece, D. J. (2009). The nature and essence of the firm. European Management Review, 6, 5-15.

Prockl, G. (2007). Logistik-Management im Spannungsfeld zwischen wissenschaftlicher Erklärung und praktischer Handlung. Wiesbaden: Gabler.

Rong, K., Hu, G., Lin, Y., Shi, Y., \& Guo, L. (2015). Understanding business ecosystem using a $6 \mathrm{C}$ framework in internet-of-thingsbased sectors. International Journal of Production Economics, $159,41-55$

Steinfield, C., Markus, L., \& Wigand, R. (2011). Through a glass clearly: standards, architecture, and process transparency in global supply chains. Journal of Management Information Systems, 28(2), 75107.

Stock, J. (1997). Applying theories from other disciplines to logistics. International Journal of Physical Distribution and Logistics Management, 27(9), 515-539.

Tokman, M., \& Beitelspacher, L. (2011). Supply chain networks and service-dominant logic: Suggestions for future research. International Journal of Physical Distribution and Logistics Management, 41(7), 717-726.

Weingarten, F., Bhakoo, V., \& Gimennez, C. (2015). The impact of host country regulatory quality on the value creation process of Ebusiness supply chains. International Journal of Production Research, 53(16), 4963-4978.

Wong, C. Y., Boon-itt, S., \& Wong, C. W. Y. (2011a). The contingency effects of environmental uncertainty in the relationship between supply chain integration and operational performance. Journal of Operations Management, 29(6), 604-615.

Wong, C. W. Y., Lai, K. H., \& Cheng, T. C. E. (2011b). Value of information integration to supply chain management: Roles of internal and external contingencies. Journal of Management Information Systems, 28(3), 161-200.

Wong, C. W. Y., Bernroider, E., \& Lai, K. H. (2015). The performance contingencies of supply chain information integration: The roles of product and market complexity. International Journal of Production Economics, 165, 1-11. 